\title{
Ontological Modeling of Certification and Inspection Process to Support Smart
}

\section{Disclosure of Product Information by Djoko Sigit}

Submission date: 19-Jun-2019 12:45AM (UTC-0700)

Submission ID: 1145181884

File name: cess_to_Support_Smart_Disclosure_of_Product_Information_OCR2.pdf (3.53M) Word count: 10267

Character count: 65751 


\section{International Journal of Public Administration in the Digital Age}

Volume 3 • Issue 2 • April-June 2016 • ISSN: 2334-4520 • eISSN: 2334-4539

An official publication of the Information Resources Management Association

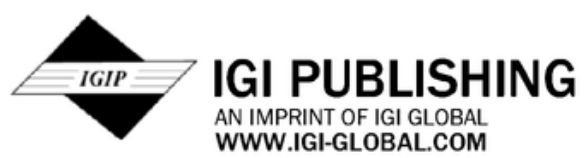

\section{EDITOR-IN-CHIEF}

Christopher G. Reddick, University of Texas at San Antonio, USA

\section{INTERNATIONAL ADVISORY BOARD}

Timothy Bagwell, American Public University System, USA

Lindy Lou West, Griffith University, Australia

\section{ASSOCIATE EDITORS}

Hisham Abdelsalam, Cairo University, Egypt

Leonidas Anthopoulos, Technological Education Institute (TEI) of Thessaly, Greece

Yu-Che Chen, Northern Illinois University, USA

Manuel Pedro Rodriguez Bolivar, Universidad de Granada, Spain

Vishanth Weerakkody, Brunel University, UK

\section{INTERNATIONAL EDITORIAL REVIEW BOARD}

Emad Abu-Shanab, Yarmouk University, Jordan

Michael Ahn, University of Massachusetts, USA

Georg Aichholzer, Austrian Academy of Sciences, Austria

Erwin Alampay, University of the Philippines, Philippines

Laura Alcaide-Muñoz, University of Granada, Spain

Hugo Asencio, California State University, USA

John Bertot, University of Maryland, USA

Shahjahan Bhuiyan, The American University in Cairo, Egypt

Kelvin Bwalya, University of Botswana, Botswana

Maria Caba-Pérez, University of Almeria, Spain

Lemuria Carter, North Carolina A \& T State University, USA

Akemi Chatfield, University of Wollongong, Australia

Susheel Chhabra, Periyar Management and Computer College, India

Pin-Yu Chu, National Chengchi University, Taiwan

Wichian Chutimaskul, King Mongkut's University of Technology Thonburi, Thailand

Michael Dahan, Sapir College, Israel

Rajeev Dwivedi, Institute of Management Technology CDL Ghaziabad, India

Jose Filho, Universidade Federal da Paraiba, Brazil

Sukumar Ganapati, Florida International University, USA

Dimitris Gouscos, University of Athens, Greece

M. Gupta, Indian Institute of Technology-Delhi, India

Teresa Harrison, University at Albany, USA

Charles Hinnant, Florida State University, USA

Vincent Homburg, Erasmus University, Netherlands

Paul Jaeger, University of Maryland, USA

Tomasz Janowski, United Nations University, China

Marijn Janssen, Delft University of Technology, Netherlands

Andrea Kavanaugh, Virginia Tech, USA

Mark Liptrott, Edge Hill University, UK

Luis Luna-Reyes, University at Albany SUNY, USA 
INTERNATIONAL EDITORIAL REVIEW BOARD

CONTINUED

Zaigham Mahmood, Debesis Education, UK

Aroon Manoharan, University of Massachusetts Boston, USA

Rony Medaglia, Copenhagen Business School, Denmark

Albert Meijer, Ultrecht School of Govemance, Netherlands

James Melitski, Marist College, USA

Anna Ni, Cal State San Bemardino, USA

Frank Ohemeng, University of Ottawa, Canada, Canada

Adegboyega Ojo, National University of Ireland, Ireland

Rebecca Levy Orelli, University of Bologna, Italy

Alois Paulin, Vienna University of Technology, Austria

Gabriel Puron Cid. Centro de Investigación y Docencias Economicas A.C. (CIDE), Mexico

Subhajyoti Ray, Xavier Institute of Management, India

Charlene Roach, The University of The West Indies. Trinidad And Tobago

Jeffrey Roy, Dalhousie University, Canada

Saqib Saced, University of Dammam, Saudi Arabia

Rodrigo Sandoval Almazán, Tecnológico de Monterrey, Mexico

Hans J Scholl. University of Washington, USA

Mehmet Sobaci, Uludag University, Turkey

Inderjeet Singh Sodhi, St.Wilfred's College, India

Genie N. L. Stowers, San Francisco State University, USA

Gregory Streib, Georgia State University, USA

Ramayah Thurasamy, Universiti Sains Malaysia, Malaysia

Lourdes Torres, University of Zaragoza, Spain

Fang Wang, Nankai University, China

F. Dianne Lux Wigand, University of Arkansas at Little Rock, USA

Mete Yildiz, Hacettepe Universitesi,Beytepe Kampusu, Turkey

Jing Zhang, Clark University, USA 


\section{Table of Contents}

\section{International Journal of Public Administration in the Digital Age}

Dolume $3 \cdot$ Issue $2 \cdot$ April-June-2016 • ISSN: 2334-4520 • elSSN: 2334-4539

An official publication of the Information Resources Management Association

\section{Special Issue on Semantic Web Technologies for Government Guest Editorial Preface}

iv Branco Ponomariov, The University of Texas at San Antonio, San Antonio, TX, USA

\section{Research Articles}

The Importance of Authorltative URI Design Schemes for Open Government Data Alexei Bulazel. Tethertess World Constellation, Rensselaer Polytechnic Institute, Troy, NY. USA Dominic Difranzo, Tethertess World Constellation, Rensselaer Polytechnic Institute. Troy, NY, USA John S. Erickson, Tethertess World Constellation, Rensselaer Polytechnic Institute. Troy, NY, USA

James A. Hendler, Tetherless World Constellation, Rensselaer Polytechnlc Institute, Troy, NY, USA

19

Des/gning a Semantic Tool to Evaluate Web Content of Government Websites

Manoj A. Thomas, Department of Information Systems, Virginia Commonwealth University, Richmond, VA, USA Jaffar A. Alalwan, Institute of Public Administration, Dammam, Saudi Arabia

37 Systems AdmInistration in Ontology-Based Applications: The Case of Citizen Relationshlp Management Assia Alexandrova, City of Fort Lauderdale, Fort Lauderdale, FL, USA Borislav lordanov, Kobrix Software, Inc.. Hollywood, FL. USA Syed Abbas, Community Information and Outreach Department, Miami-Dade County, FL, USA Phani Upadrasta, Syniverse Technologies, Tampa, FL, USA Michael Sarasti. Community Information and Outreach Department, Miami-Dade County, FL, USA Thomas Hilpold, Community Information and Outreach Department. Miami-Dade County, FL. USA

47 An Innovative Govemment Architecture with Sernantic Technology Wout Hofman. Department of Technical Science, The Netherlands Institute of Applied Technology (TNO), Soesterberg, the Netheriands

67 Opportunities and Challenges of Policy Informatics: Tackling Complex Problems through the Combination of Open Data, Technology and Analytics

Gabriel Puron-Cid, Centro de Investigacion y Docencia Economicas (CIDE). Aguascalientes, Mexico

J. Ramon Gil-Garcia, University at Albany, State University of New York. Albany. NY, USA \& Centro de Investigacion y Docencia Economicas (CIDE). Aguascalientes, Mexico

Luis F. Luna-Rayes, University at Albany, State University of New York, Albany, NY, USA

87 Ontological Modelling of Certification and Inspection Process to Support Smart Disclosure of Product Information

Djoko S. Sayogo, Center for Technology in Govemment, University at Albany. Albany, NY, USA \& University of Muhammadiyah at Malang, Malang, Indonesia

Weijia Ran, Department of Informatics, University at Albany, SUNY, Albany, NY, USA

Gin K. Tayi, School of Business, University at Albany, SUNY, Albany, NY, USA

Joan 4 S. Luciano, Tetherless World Constellation, Rensselaer Polytechnic Institute, Troy, NY. USA

Luis Luna-Reyes, Department of Informatics, University at Albany, SUNY, Albany, NY, USA

Nicolau Depaula, Department of Informatics, University at Albany, SUNY, Albany, NY, USA

Holly Jarman, School of Public Health, University of Michigan, Ann Arbor, MI, USA

Jing Zhang, Graduate School of Management, Clark University, Worchester, MA, USA

Jana Hrdinova, Center for Real Estate. Fisher College of Business, Ohio State University, Columbus, OH. USA

Deborah Lines Andersen, Department of Informatics, University at Albany, SUNY, Albany, NY, USA

David F. Andersen, Rockefeller College of Public Affairs \& Policy, University at Albany. SUNY, Albany, NY. USA

Theresa Pardo, Center for Technology in Govemment, University at Albany, Albany, NY, USA

Cop1right

The International Joumal of Public Administration in the Digltal Age (IJPADA) (ISSN 2334-4520; elSSN 2334-4539), Copyright (e) 2016 IGI Global. All rights, Including translation into other languages reserved by the publisher. No part of this joumal may be reproduced or used in any form or by any means without written permission from the publisher, except for noncommercial. educational use including classroom teaching purposes. Product or company names used in this journal are for identification purposes only. Inclusion of the names expressed in this joumal are those of the authors but not necessarily of IGI Global. 


\section{Ontological Modeling of Certification and Inspection Process to Support Smart Disclosure of Product Information}

Djoko S. Sayogo, Center for Technology in Government, University at Albany, Albany, NY, USA \& University of Muhammadiyah at Malang, Malang, Indonesia

Weijia Ran, Department of Informatics, University at Albany, SUNY, Albany, NY, USA

Giri K. Tayi, School of Business, University at Albany, SUNY, Albany, NY, USA

Joanne S. Luciano, Tetherless World Constellation, Rensselaer Polytechnic Institute, Troy, NY, USA

Luis Luna-Reyes, Department of Informatics, University at Albany, SUNY, Albany, NY, USA

Nicolau Depaula, Department of Informatics, University at Albany, SUNY, Albany, NY, USA

Holly Jarman, School of Public Health, University of Michigan, Ann Arbor, MI, USA

Jing Zhang, Graduate School of Management, Clark University, Worchester, MA, USA

Jana Hrdinova, Center for Real Estate, Fisher College of Business, Ohio State University, Columbus, OH, USA

Deborah Lines Andersen, Department of Informatics, University at Albany, SUNY, Albany, NY, USA

David F. Andersen, Rockefeller College of Public Affairs \& Policy, University at Albany, SUNY, Albany, NY, USA

Theresa Pardo, Center for Technology in Government, University at Albany, Albany, NY, USA

\section{ABSTRACT}

The increasing number of certification schemes diminishes the utility of certifications as private regulation and creates several policy challenges. The undergoing efforts to help consumers verify the accuracy of information created by private regulation mechanisms such as certification are currently confronted with the complexities of certification and labeling systems and the difficulties in linking data points across various certification schemes. This paper presents the development of certification and inspection ontology to support smart disclosure of product information. This study proposes that the resulting ontology enables information integration and standardization thus supporting knowledge discovery and sharing by synthesizing information across disparate data sources that is valuable for informing data-driven policy formulation. The ontology also supports standardization of an agreed set of terms and semantics for currently fragmented certification and inspection schemes to support comparability across different certification schemes. The accuracy and consistency of the proposed ontology are verified by using current reasoning tools to run queries based on a set of predefined competency questions.

\section{KEYWORDS:}

Certification Schemes, Fairtrade, Ontology, Ontology for Product Certification, Private Regulation, Product Packaging Information, Smart Disclosure, Sustainable Labelling Schemes 


\section{INTRODUCTION}

Governments worldwide have endorsed the use of private regulations to manage the complexity of transnational trading relationships. These regulations rely on a coalition of non-governmental actors to add additional layers of rules and fill a gap in regulatory capability at global level (Bartley, 2007, 2011; Mayer \& Gereffi, 2010). This gap is a result of the reluctance of many governments to agree to binding transnational trade standards (Bartley, 2007). Private regulations offer a way to codify and monitor compliance of organizations with given safety, quality, social and environınental standards. Voluntary certifications, such as organic or Fairtrade, represent one particular type of private regulation that certifies the social and environmental conduct of companies. These certifications are based on voluntary mechanisms and rely on market dynamics - the interaction of companies, consumers and other stakeholders - for enforcing compliance (Mayer \& Gereffi, 2010). Companies in turn use the certification to preserve their reputation, solicit trust from consumers, and achieve product differentiation advantage in the marketplace.

The number of certification schemes has expanded rapidly since 1990s (Bartley, 2011; Taylor, Murray, \& Raynolds, 2005). For example, the eco-label index is currently tracking 435 eco labels worldwide in 25 industry sectors. On one hand, development of eco-labels provides consumers with more purchasing options. On the other hand, the rapid proliferation of certification schemes hinders the ability of consumers to comprehend the meaning behind each certification. The lack of understanding could influence market dynamics by complicating consumers' purchasing decisions and providing opportunity for irresponsible companies to take advantage of consumer confusion. Survey by TerraChoice in 2010 conducted in 24 stores in the U.S. and Canada claimed that more than $95 \%$ of the 5,300 products being observed committed at least one sin of green-washing' (Makower, 2010; Swain, 2011). The problem with green-washing is that it could lead to information asymmetry between consumers and companies by diluting the meaning of private regulation.

The situation outlined above has created policy challenges since governments can no longer solely rely on the market dynamics to enforce sound practices of private regulation. The effectiveness of private regulation to represent company's true commitment toward social and environmental policy becomes questionable (Ramus \& Montiel, 2005). As a result, several efforts are being undertaken to help consumers verify the accuracy of product information provided by private regulatory frameworks, including information about voluntary sustainable certifications. In the private sector, consumer advocates such as GoodGuide, Barcoo or NuVal, created web and mobile tools and applications to help consumers better understand the consequences of their purchases in the context of healthy and ethical consumption (Luna-Reyes et al., In Press). Watts \&Weyner (2011) coined this type of applications and tools mobile technology-mediated ethical consumption (MTEC) tools (Watts \& Wyner, 2011). In public domain, government entities, particularly in the U.S., have recently started promoting an information policy called smart disclosure to give consumers more control over their own data to make informed choices about their purchases (Sunstein, 2011).

However, the complexities of certification and labeling systems and the difficulties in linking data points across various certifications complicate the efforts to help consumers make informed choices. For example, majority of existing MTECs assign high environmental score to any product that is certified by a voluntary sustainable certification scheme. However, certifications differ in the vigor of their standards, which does not get represented in the evaluation. The inability of the current MTECs to uncover further information behind each label diminishes the value of their product evaluation. Currently, the smart disclosure efforts by the U.S. government focus only on the disclosure of product usage and consumption history of products that have continuous buying properties such as banking, electricity, or mobile usage. Smart disclosure policies do not yet address disclosure of product-attribute information such as sustainability, social impact and product provenance. Creating effective data architecture that enables consistent mining of diverse certification and labeling data as well as facilitating comparability across certifications could generate credible information that 
consumers can use to make informed purchasing decisions. For instance, application and usage of such architecture could help consumers better understand the social and environmental consequences of their purchases. Consumers could maximize their satisfaction by purchasing products that truly reflect not only their economic value but also social and environmental values.

This paper describes the development of certification and inspection ontology to support smart disclosure of product information. Theprimary focus and contribution of thispaper is in systematically describing the ontological modeling process of certification and inspection schemes to support smart disclosure of product information that is valued by a consumer as she makes a purchasing decision. As such, this paper does not delve into the detailed technical design and development of an overarching certification and inspection data infrastructure that would be needed to produce virtual certificates. Such an effort is reported in detail in (Luciano et al., 2013). Also the current paper does not describe the necessary governance mechanisms needed for implementation of the ontology-based data architecture, or explains in detail the trustworthiness issues which are applicable to certification and inspection schemes. The issues of governance and trustworthiness are discussed in detail in our earlier paper (Luciano et al., 2013).

This study argues that ontology for certification and inspection enables two major uses: integration and standardization of certification and inspection data. First, the ontology provides a method to integrate certification information from various data sources. Second, the ontology enables standardization of an agreed set of terms and semantics for the currently fragmented certification and inspection ecosystem. These two major uses are necessary to support the implementation of smart disclosure for product information. We also highlight the potential benefits of the certification and inspection ontol $4 \mathrm{gy}$, such as improvements to consumer consumption decision process.

The paper is organized into seven sections, including this introduction. Section two presents literature review detailing the role certification and inspection ontology can play in supporting smart disclosure and enhancing effectiveness of private regulation. Section three presents the structure of the certification and inspection domain. Section four discusses the methodology used to develop our proposed ontology, namely the iterative process involving specification, conceptualization and verification. Section five describes the development of our ontology from three aspects: specification of ontology in terms of scenario and motivating questions. conceptualization of ontology, and verification of ontology. Section six discusses the envisioned value of our proposed ontology and the policy benefits and implications of our proposed ontology. And finally section seven presents our conclusions.

\section{PRIVATE REGULATION, SMART DISCLOSURE AND THE CERTIFICATION AND INSPECTION DATA ARCHITECTURE}

Private regulation is a governance system formed by a coalition of non-governmental actors to codify and monitor the conduct of private entities to enable a broad range of economic activities free of negative externalities such as child labor (Bartley, 2007; Büthe, 2010a, 2010b; Mayer \& Gereffi, 2010). Private regulation is designed to use market pressure to regulate the behavior of industry's actors (Bartley, 2007; Mayer \& Gereffi, 2010) and to add layers to the existing laws, regulations and standards enacted by governments (Bartley, 2011). Private regulation takes many forms (standards, codes of conduct and certification systems) and is organized in three different formats: a) voluntary policies and codes of conduct developed and adopted by a company, b) standards developed by industry and/or trade associations and adopted by companies, and c) third-party systems certifying the compliance to particular standard (Bartley, 2007; Mayer \& Gereffi, 2010).

The third form of private regulation, third-party certification system, is deemed more trustworthy than the other two due to the independent monitoring and compliance processes that significantly reduce the possibility of conflict of interest (Jahn, Schramm, \& Spiller, 2005). Consumers also recognize the utility of certifications and labels to induce trust in a specific brand (Carrigan \& Attalla. 
2001; Janssen \& Hamm, 2011; Polonsky, Bhaskaran, \& Cary, 2011). They use certificates or labels to guide their purchasing decisions (Carrigan \& Attalla, 2001), even if some might have limited understanding of the meaning behind the particular label or certificate (Carrigan \& Attalla, 2001; Janssen \& Hamm, 2011; Polonsky et al., 2011). For instance, consumers positively correlate organic certification with greater level of trust in the product (Janssen \& Hamm. 2011).

On the other hand, third-party certifications have two notable limitations: a) high degree of variation among different certifications and labels, and b) the process of certification is generally not transparent (Mayer \& Gereffi, 2010). The extensive diversity of third-party certifications have led researchers to question their credibility and legitimacy (Jahn et al., 2005; Taylor et al., 2005). The lack of transparency in certification processes diminishes the ability of consumers to understand the meaning behind a particular certification and decreases the utility of certification schemes in assisting consumers with making informed choices (Jarman et al., 2011; Luna-Reyes et al. In Press).

A number of studies argue for the re-construction of the choice architecture by providing consumers with smart disclosure to help them make informed decision (Benartzi, Peleg, \& Thaler, 2012; Thaler, Sunstein, \& Balz, 2010; Thaler \& Sunstein, 2008). Smart disclosure is an information policy enacted by the U.S. government in 2011 to provide consumers with greater access to standardized data in machine readable formats in timely manner to help them make informed choices (Howard, 2012; Sunstein, 2011). By altering the choice architecture through smart disclosure, the utility of certifications to consumers making choices can be enhanced. Smart disclosure of product and certification data could potentially help consumers better understand the meaning behind labels. The provision of timely and relevant data in standardized and machine readable format in smart disclosure tools could enable comparability across different certification schemes, which in turn would allow for an assessment of the credibility, quality and legitimacy of the certification.

The capability to compare different certification schemes to support smart disclosure of product information requires connecting a large amount of data from various sources. Considering that integration of heterogeneous data across many sources is a major focus of semantic web technologies (Bio, 2013), the development of this capability could benefit from the application of semantic web technologies (Gonzalez, 2013). This is true for two reasons. First, the envisioned architecture needs to integrate various data points across the supply chain. Second, it is not possible to anticipate every query a consumer can pose and to know in advance what data and information will need to be extracted from which sources to satisfy these queries. Semantic web technology offers flexibility and expansiveness in integrating various data since it "takes an overlay approach that virtualizes information from existing (non-semantic) source systems, imports that information into the semantic web data model, and then links together information between various connected systems" (Bio, 2013). The key utility of semantic technology is the ability to capture data in ontologies and map them via related concepts (Semy, Pulvermacher, \& Obrst, 2004).

\section{THE STRUCTURE OF RELIABLE THIRD PARTY CERTIFICATION AND INSPECTION}

A number of studies point to two major components signifying reliable third party certification and inspection: agent and evaluation process (Albersmeier, Schulze, Jahn, \& Spiller, 2009; Deaton, 2004; Hatanaka, Bain, \& Busch, 2005; Jahn et al., 2005; Tanner, 2000). In general, agents involved in the certification process are standard setting organizations, certification bodies, accreditation bodies, and applicants (Albersmeier et al., 2009; Jahn et al., 2005). The certification body will assign the inspection process to auditor/inspector and certifying/evaluating officer ${ }^{2}$. Relationships among these agents are governed through the evaluation process (Albersmeier et al., 2009; Jahn et al., 2005), which represents the "heart" of the certification system (Deaton, 2004).

Jahn et al (2005) describe three different types of evaluation processes depending on the relationship between agents: a) monitoring process to describe relationship between standard setting 
and certification body; b) accreditation process for relationships between accreditation body and standard setting and certification body; and c) certification process to describe relationship between certification body and the applicant (Jahn et al., 2005). Documents and web content analysis of FLO (Fairtrade Labeling Organization) ${ }^{3}$ International and UTZ Certified ${ }^{4}$ further indicate that evaluation process in general uses three documents, namely: a certification standard, an inspection report and a certificate (FLO, n.d.; UTZ Certified, n.d.). Standards are used to guide the evaluation process. Certification body uses standards as guidance during the certification process after the standard is translated into compliance criteria or indicators. The inspection report and certificate are the output of the evaluation process (FLO, n.d.; UTZ Certified, n.d.). Auditor/inspector creates an inspection report after completing an inspection and successful inspection leads to the publication of a certificate to signify applicant's compliance to the standard.

The key to a reliable third party certification is "true independence" and objectiveness of the evaluation process (Deaton, 2004; Tanner, 2000). Independence is crucial for signaling product quality because it removes conflicts of interest from the evaluation process (Deaton, 2004; Tanner, 2000), which subsequently increases the quality of certification process. Thus, independence of third party certification increases the costs of certification especially for applicant with low product quality (Deaton, 2004). Cost of certification is higher for applicant with low product quality than applicant with high product quality. Applicants with low product quality incur more expenses to comply with higher quality and stringent requirements of an independent third party certification. The second indicator is objectiveness of the evaluation process. Objectiveness of the evaluation decision is met if the assessment processes and criteria are objective. As argued by Deaton, the decision is objective if the inspection or audit processes meet qualifications specified by generally accepted principles or standards (Deaton, 2004). These generally accepted principles and standards must be created by a higher level of authority than the certification or standard setting body, such as accreditation body (Tanner, 2000).

\section{METHODS}

We utilized two methods in our modeling approach: a) method to collect data to support the ontology development, and b) method for ontology building. This section briefly discusses these methods.

\subsection{Data Collection Methods}

We used a combination of interviews and focus groups, document analysis, and exemplar development to collect data in order to understand the domain, extract concepts and create motivating scenarios and competency questions. Detailed description of our data collection method is as follows.

- Interviews and Focus Group Discussions: We conducted interviews and focus group discussions. The focus group involving experts in the coffee supply chain and NGOs focusing on sustainable certified products was conducted to understand the certification and inspection in the whole supply chain. To supplement this data, we conducted interviews with three different certification bodies: Control Union, Fairtrade USA, and Fair for Life.

- Document Analysis: We conducted an analysis of documents published by certification bodies, particularly Flo-Cert ${ }^{5}$ and UTZ Good Inside. Examining the documentation enabled us to extract important concepts and terms in certification and inspection, as well as gain understanding of the relationship among them.

- Exemplar and Audit Reports: The two above-mentioned activities enabled us to better understand the process, structure, and concepts used in certification and inspection. We strengthened our understanding with exemplar and audit reports. The exemplar reports contain the results of interviews and observations of traceability and certification of specialty coffee sold by Café Rue Champagneur in Montreal, which is produced by a cooperative in Mexico, 
Tosepan Titataniske. The exemplar supplies us with detailed information about the producers, distributors, roasters, and their relationships. The audit reports were obtained from Flo-Cert and UTZ. These reports enable us to better understand the implementation of concepts, processes and relationships.

\subsection{Ontology Building Methods}

Our methodology for building the certification and inspection ontology follows an iterative life-cycle approach adapted from commonly used ontology-development methods including the METHONTOLOGY (G6́mez-Pérez, Fernandez-Lopez, \& Corcho, 2004), the 101 Method (Noy \& McGuinness, 2001), and an ontology-development process for developing government ontology (Brusa, Caliusco, \& Chiotti, 2006). The ontology development life cycle proposed in the abovementioned studies includes three phases - specification, conceptualization, and implementation and verification.

- The Specification Phase focuses on understanding the domain to define the scope and limits of the ontology. This phase includes collecting relevant data from different sources, understanding the domain knowledge with the help of a domain expert, resolving conflicts in various data representations, and extracting important and common concepts. The results of the specification phase are: a) a set of important and common concepts from the domain, and b) motivating scenarios and competency questions to define the boundaries of the ontology. These scenarios and questions can also be used for ontology verification in the later implementation and verification phase.

- The Conceptualization Phase involves identification of classes, relations, attributes, and instances toconceptualize the ontology. We used Unified Modeling Language (UML) to describe and refine identified classes, instances, and relations among them.

- The Implementation and Verification Phase: This stage involves the efforts to implement and verify our proposed ontology. We used Protégé 4.1 as the tool to implement the ontology. We chose Protégé for three reasons. First, Protégé provides flexible plug-and-play environment for ontology development (Brusa et al., 2006). Second, an ontology developed using Protégé can be easily exported into different formats including RDF scheme. Third, Protégé has built-in queries to help us verify the consistency of our ontology. We used two approaches to verify and validate our ontology. First, we ran the reasoning embedded in Protégé, in particular Hermit ++ and Pellet to verify the consistency of our ontology. Second, we used our competency questions to validate our ontology by using the questions to query the ontology and examine the result.

The above three-phase procedure is an iterative process. As shown in Figure 1, the problems and issues that we found in the implementation and verification phase helped us to re-define the scope of the ontology and re-specify the ontology. This led to another round of specification, conceptualization, implementation, and verification. We refined our ontology through this iterative process.

\section{BUILDING CERTIFICATION AND INSPECTION ONTOLOGY FOR CERTIFIED SUSTAINABLE PRODUCTS}

This section describes in brief the process used to develop three ontologies, namely: CerTIN (Certification and Inspection Ontology), CiTruST (Certification and Inspection Trustworthy) and FLO ontology. CerTIN is a proposed ontology to represent the processes for certification and inspection for sustainable products. CiTruST is a proposed ontology to represent indicators of trustworthy certifications based on certification and inspection processes. FLO ontology is ontology to represent the certification and inspection process used by Fairtrade Labeling Organization. Detailed description 
Figure 1. Three-phase ontology development process (adapted from Gomez-Perez et al., 2004)

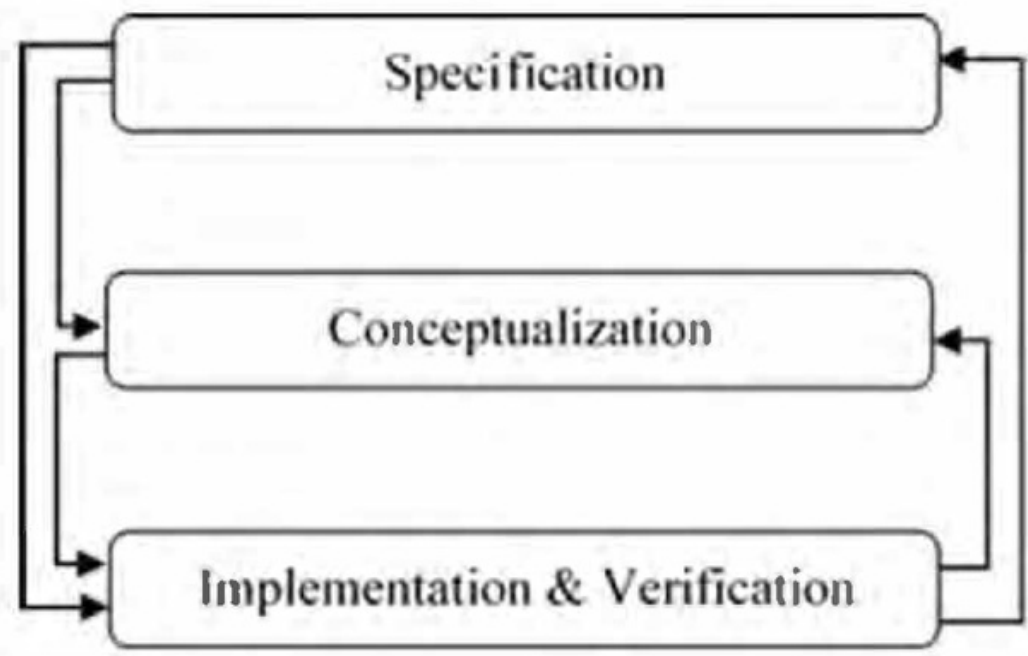

of each of these ontologies is presented in section 5.2 below. As described above, we followed three major steps in the development of these ontologies: a) specifying the goals and scope through motivating scenario and competence questions, b) conceptualizing the ontologies using top down approach, and c) verifying and validating the proposed ontologies.

\subsection{Specification of the Proposed Ontology: Developing Motivating Scenarios and Competency Questions}

We present two scenarios to demonstrate how the use of CerTIN and FLO ontology could support smart disclosure and generate value. We also created sets of competency questions to guide us in developing the ontology and later to evaluate whether the resulting ontology is as we expected. The scenarios are intended to show bow the ontology can help consumers acquire better information to make informed purchase decisions and help consumer advocates obtain information regarding the certification and inspection process, including production conditions and the welfare of the workers producing a product that consumers are interested in.

\subsubsection{Scenario1: Assessing the Robustness of No Child Labor Policy for Particular Certification Scheme}

The first scenario describes the use of the ontology to verify that a product is not tainted with child labor. A consumer advocate may want to trace the certification information to verify the compliance of the producer to the "No Child Labor" policy. This scenario envisioned that a consumer advocate, using a system based on the ontology, identifies a certification body based on the certification label attached to the product, and accesses its database to retrieve the appropriate inspection reports. In this scenario, the consumer advocate is not interested in measuring the performance of the producer, but rather the robustness of Child Labor policy of the particular certification. The consumer advocate wants to extract the list of criteria governing "No Child Labor" from the particular certification by sending a query to the certification body, such as: "what are the core indicators for child labor issues for this label?" 


\subsubsection{Scenario2: Assessing the Reliability of Certification Processes}

In the second scenario, a consumer advocate is interested in evaluating the reliability of certification processes across different certification schemes. This scenario emerges from a situation in which consumers are unsure of the differences between various certifications and labels attached to a product. The consumer advocate needs to compare certification processes to inform the consumer of the differences between various certification schemes. There are three possible data sources that the consumer advocate can tap into: a) expert opinion, b) information on the web, and c) information released by the certification body. Each of these sources has weaknesses. For example, expert opinion can be affected by subjective biases and information found on the web suffers from insufficient traceability and data provenance. The consumer advocate needs the ontology to map the information gathered from the three sources to provide strong recommendation about the reliability of the certification process undertaken by a particular certification scheme. A consumer might launch query to the consumer advocate, "show me certification that has most reliable evaluation process?" Having knowledge about the structure of certification processes, the consurner advocate could take the consumer's query and modify it into more complex query such as: "Which certification body is accredited by an accreditation body, is external to the standard setting organization, and completed document and field inspection in their certification process?"

\subsubsection{Competency Questions}

In addition to the scenarios, we utilized competency questions drawn from the motivating scenarios. These questions were used to verify if the ontology contained enough information to answer the various queries. The questions also specify the level of detail required from the proposed ontology to respond to the queries. Some of the competency questions are shown in Table 1 below.

\subsection{Conceptualization of the Proposed Ontology}

We follow top-down approach in conceptualizing our ontology by first defining the most general concepts in the domain. Top-down approach is more appropriate for developing a shared ontology especially when the concept encompasses a very complex and large number of systems (Cui, Jones, \& O'Brien, 2001). Using this approach, we created three different ontologies (Figure 2). First, we developed the CerTIN "upper level certification ontology" (global), which captures high level description of certification and labeling schemes. Second, we supplemented CerTIN ontology with "detail ontology" (local) that focuses on detailed certification process using FLO labeling as an example and call it FLO ontology. Third, we created ontology to specify the reliability of certification and inspection that we called CiTruST ontology.

The relationship between global and local ontology (Figure 2) can be described as follows. The global ontology, CerTIN can map their concepts (classes and properties) into local ontology, FLO and

Table 1. Competency questions

\begin{tabular}{|l|}
\hline Simple Questions \\
\hline - Who are the certification bodies? \\
\hline - Who are the standard setting bodies? \\
\hline - Who are the accreditation bodies? \\
\hline Complicated Questions \\
\hline - Who is the inspector for $[\mathrm{xxx}]$ certification? \\
\hline - Which certification body is accredited by $[\mathrm{xxx}]$ accreditation body? \\
\hline - Which certification body conducts field inspection? \\
\hline
\end{tabular}




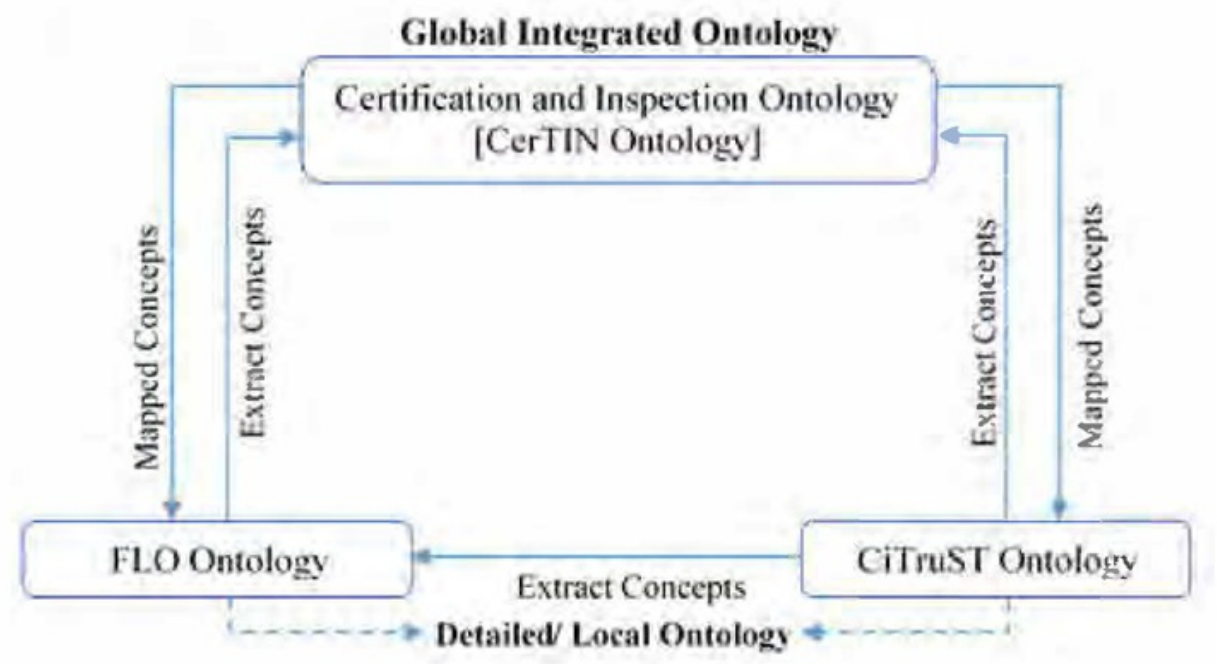

CiTruST. This mapping ensures interoperability across different local ontologies because these local ontologies use the same concepts from the global ontology. On the other hand, the global integrated ontology could extract detailed concepts from the local ontologies, which adds expansiveness to the global ontology.

\subsubsection{Upper Level Ontology: Certification and Inspection Ontology (CertIN)}

Certification and inspection ontology (CertIN) defines the domain of a certification system. We envision CerTIN as an integrated global ontology that provides a shared vocabulary for all connected local ontologies (Choi, Song, \& Han, 2006). As such, CertIN only describes the higher level definition of a certification system that serves as an overarching architecture connecting local ontology for each certification and labeling scheme. In building the CertIN ontology we used the standard definition of class and property available from existing ontology literature. In particular, we adopted classes and properties from three ontologies: Dublin $\mathrm{Core}^{6}{ }^{6} \mathrm{FogF}^{\prime}$ and Good Relation ${ }^{8}$, which are regarded as the good ontology ${ }^{9}$ by W3C (World Wide Web Consortium). For instance, we use the agent definition from Dublin Core and the document definition from FoaF.

CertIN consists of five major components: agent, document, object of certification, inspection process in certification, and evaluation decision. As previously explained in the methods section, these components were identified from document analysis across different certification schemes, as well as interview findings. A summary of subclasses within each class is presented in Table 2 and a brief description of each class is as follow.

- Agent refers to entities involved in the process of certification. An agent can be an individual or an organization. Agent can have five different roles in a certification system: applicant, certifier ${ }^{10}$, certifying officer, inspector, and standard setter.

- Document refers to the key documents that are used in, or are produced as an outcome of the certification and inspection process. There are three major documents: a) a certificate to represent the outcome of certification process, b) an inspection report to represent the result of inspection, and c) standards and compliance criteria, which are the principles that guide the certification process. 
Table 2. Classes and sub-classes in Certin ontology

\begin{tabular}{|c|c|}
\hline Class & Sub-Class \\
\hline \multirow[t]{5}{*}{ Agent } & Applicant \\
\hline & Certifier \\
\hline & Inspecior \\
\hline & CertifyingOfficer \\
\hline & StandardSetter \\
\hline \multirow[t]{3}{*}{ Document } & Certificate \\
\hline & InspectionReport \\
\hline & Standard \\
\hline \multirow[t]{2}{*}{ Inspection Process in Certification } & DocumentInspection \\
\hline & FieldInspection \\
\hline \multirow[t]{3}{*}{ Evaluation Decision } & Conrective Measure \\
\hline & NonConformity \\
\hline & ObjectiveEvidence \\
\hline \multirow[t]{3}{*}{ Object of Certification } & BusinessEntity \\
\hline & Process \\
\hline & ProductOrService. \\
\hline
\end{tabular}

- Object of Certification refers to the object applying for certification. In general, there are three objects of certification, namely: products, processes, and business entities.

- Inspection Process in Certification refers to the process of gathering evidence to assess the compliance of an applicant or object of certification with the standards and compliance criteria set by the certifier and standard body. There are two kinds of inspection: document inspection and field inspection.

- Evaluation Decision refers to the decision made after an inspection is conducted to assess the extent to which object of certification adheres to given certification standards and criteria. The evaluation decision criteria refer to the applicant's non-conformity to the standard, based on objective evidence encountered during the inspection, along with an action required (corrective measure) to remedy the non-conformity. Evaluation decision consists of three classes: nonconformity, corrective measure, and objective evidence.

The relationship among the classes of CerTIN ontology is presented in Figure 3 below. Each rectangle in Figure 3 represents a class. Arrows between classes are annotated by property names and represent object properties defining the relationship between classes. Each arrow can be read as a triple $<$ ClassXpropertyNameClass Y $>$. For instance, relationship between an applicant and an inspection report in Figure 3 can be represented as: <ApplicantrightHolders/nspectionReport>, meaning, applicant holds the rights to an inspection report.

\subsubsection{Detailed Ontology: FLO Centification Ontology}

We supplement the CerTLN ontology with an ontology depicting the certification process of FLO certification scheme to demonstrate the connection of local ontologies to the higher level global CertiN ontology. As mentioned in section 5.1., we also mapped CerTIN to existing "good" ontology. This 


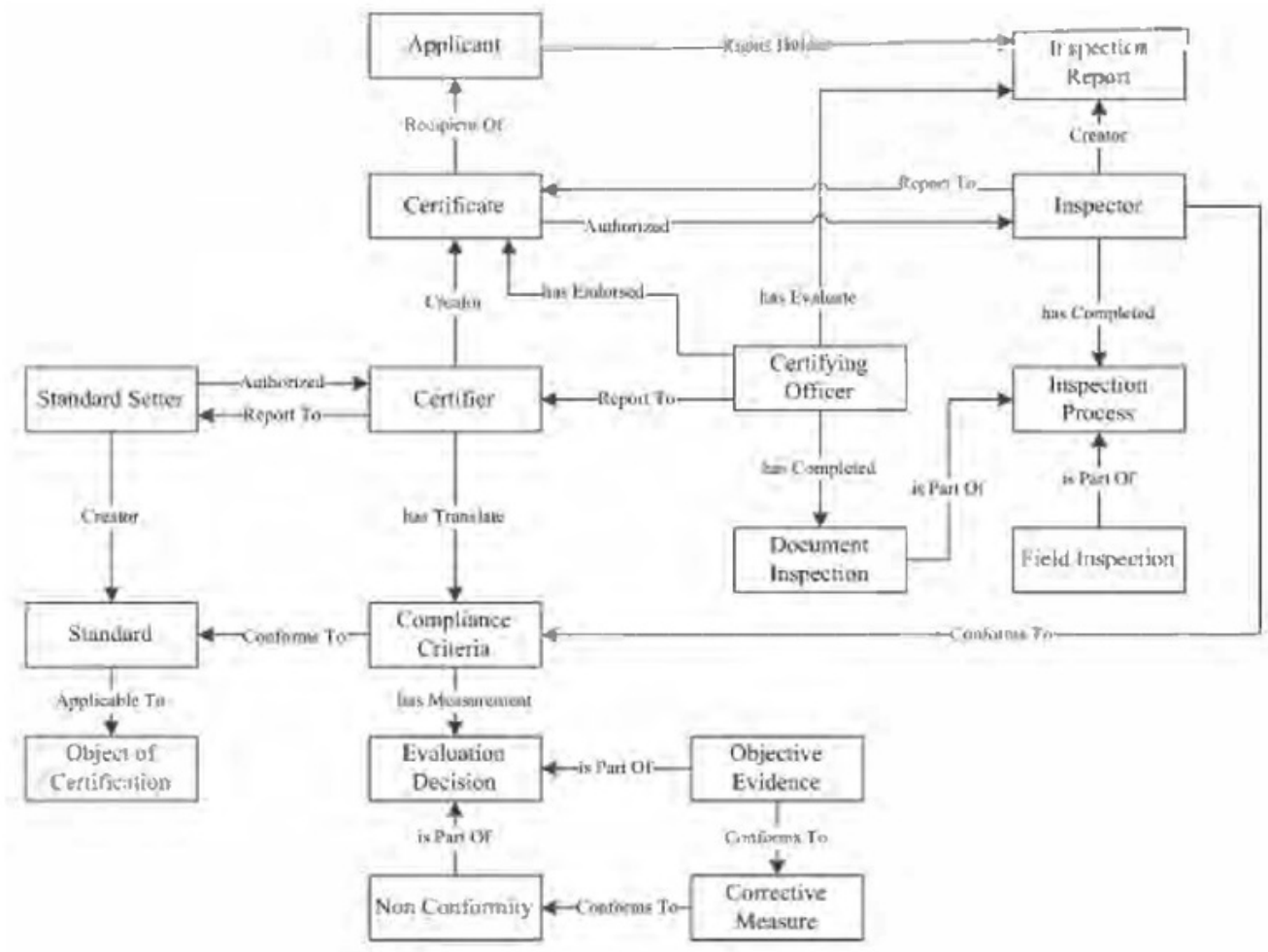

ontology mapping is crucial for combining distributed and heterogeneous ontologies and to enhance its interoperability (Choi et al., 2006).

FLO ontology is important to provide additional indicators for assessing the trustworthiness of a certification scheme in terms of detailed measurement of certification. In FLO ontology, the sub-classes of CerTIN ontology are classified further into detailed classes with detailed properties (Table 3). For instance, Applicant is classified further into SmallProducerOrganization and TradingOrganization. Each of these detailed classes will have detailed properties defining the class. For instance, the only legal status for SmallProducerOrganization recognized in FLO standard is cooperative. Thus, we can represent the relationship as <SmallProducerOrganizationhasLegalStatusCooperative $>$. Cooperative is an instance in this relationship. FLO also requires the applicant to appoint one person as a contact liaison with FLO throughout the certification cycle. This relationship can be represented as: $\langle$ SmallProducerOrganizationhasContact Contact $\rangle$.

The most important detail in the FLO ontology is the classification of compliance criteria into the properties to define conformity to these criteria. In FLO, compliance criteria are classified based on the topic of interest, namely: child labor issue, freedom from discrimination, and other. In turn each compliance criterion in FLO has evaluation decision: a) confirmation of non-compliance called non-conformity, b) corrective measure to resolve non-conformity, and c) objective evidence as a means to prove compliance. FLO system assumes that non-existence of non-conformity automatically indicates conformity. 
Table 3. Classes and sub-classes in Certin ontology

\begin{tabular}{|c|c|c|c|c|}
\hline \multicolumn{2}{|c|}{ CerTIN Ontology } & \multicolumn{3}{|c|}{ FLO Ontology* } \\
\hline Class & Sub-Class & Cluss & Sub-Class & Sub-Class \\
\hline \multirow[t]{6}{*}{ Agent } & \multirow[t]{2}{*}{ Applicant } & SmallPruducerOryanization & & \\
\hline & & Thuding Orxanization & & \\
\hline & Centifier & - & & \\
\hline & Inspector & Inspector & & \\
\hline & CerrifyingOfficer & CertifyingOfficer & & \\
\hline & StandardSetter & - & & \\
\hline \multirow[t]{9}{*}{ Docuinent } & Cerificate & Certificale & & \\
\hline & InspectionReport & InspectionReport & & \\
\hline & \multirow[t]{7}{*}{ Standurs } & \multirow[t]{7}{*}{ ComplianceCrtieria } & \multirow[t]{5}{*}{ ChildLahorCriteria } & NoEmploymentOfChildmenUnderAgeOfIS \\
\hline & & & & NoWorseFormOfLabor \\
\hline & & & & Exisence OfConirolMeasureForChildLobor \\
\hline & & & & EnvareHealhthyndSafetyWarking Condition \\
\hline & & & & Suifable WorkConditionAndHour \\
\hline & & & FreedomFromDiscrimination & $\langle\ldots\rangle$ \\
\hline & & & $\langle+\rangle$ & $\langle\ldots\rangle$ \\
\hline \multirow{2}{*}{$\begin{array}{l}\text { Inspection } \\
\text { Process in } \\
\text { Certification" }\end{array}$} & Doctunenthuspertion & Documenthuspection & & \\
\hline & Fieldlnspection & Fieldilnspection & & \\
\hline \multirow{3}{*}{$\begin{array}{l}\text { 'Evaluation } \\
\text { Decisios' }\end{array}$} & Corrective Measuse & Corrective Measure & & \\
\hline & NanConformity & Non Confurnity & & \\
\hline & ObjectiveEvidence & ObjectiveEvidence & & \\
\hline \multirow{3}{*}{$\begin{array}{l}\text { 'Object of } \\
\text { Certification' }\end{array}$} & BusinessEntity & - & & \\
\hline & Prockess & . & & \\
\hline & ProdtetorService & ProductOrSenvice & & \\
\hline
\end{tabular}

-Selected sub-classes from FLO ontology

A compliance criterion is constructed with several restrictions, as defined in the FLO standard, by specific timeline, criteria types, measurement of the criteria and organization applicability. The existence or nonexistence of these restrictions relates to the conformity to the criteria and could further define the level of trustworthiness of the certification. In addition to the indicator of the criterion, these restrictions represent the properties of the criterion. In our FLO ontology, these properties are represented as object properties if they connect classes to other classes, and data properties if they connect classes to data (instances/individuals) (Horridge, Knublauch, Rector, Stevens, \& Wroe, 2004). A class in the ontology represents an abstract object such as compliance criteria; an instance or individual is a concrete object such as: children under age 15.

To illustrate the representation of compliance criteria, we used and re-formulated criterion for child labor under the age of 15 from FLO Labeling International. FLO criterion for child labor is reformulated as: "Criteria for no employment of children under the age of 15 is satisfied if the auditor found no indication of children under the age of 15 being employed. This criterion is only applied to the members of the organization. This criterion is part of core standards and is applied in initial audit and thereafier'. This narrative consists of combination of classes and instance. The class is presented in italic, the individual is presented within double quotation mark, the restriction 
is presented in bold, and the property, either data or object property, is presented with a verb as the first word, such as "has". This narrative can be presented formally as:

$<$ NoEmployementofChildrenUnderAgeof15 hasEvaluationDecision some

'Evaluation Decision'>

<NoEmployementOfChildrenUnderAgeOf15 hasCriteriaType value "Core

Criteria">

$<$ NoEmployementofChildrenUnderAgeof15 hasTimeline value "Initial

Audit">

<NoEmployementOfChildrenUnderAgeOf15 hasApplicability value

"Members of Organization">

<NoEmployementofChildrenUnderAgeof15 hasIndicator value "There

are no Children under the age of 15 years employed">

\subsubsection{CiTruST Ontology: Ontology for Evaluating the Reliability of Certification Process}

In addition to the global CerTIN ontology and the detailed FLO ontology, we created an ontology for evaluating the reliability of a certification process that we called CiTruST ontology. This ontology was created to further demonstrate the scalability of CerTIN ontology as an integrated global ontology that provides a shared vocabulary for other ontologies. Consequently, CiTruST ontology uses the classes and properties from CerTIN ontology to define the reliability of certification processes. To create CiTruST ontology, we first had to determine the indicators of a "good" certification process through literature review, document analysis and interviews.

We started with the basic structure of a certification as an indicator of its reliability. Some components of the basic structure of a reliable certification process are the accreditation body, certification body, standard setter, and monitoring process (Albersmeier et al., 2009; Deaton, 2004; Jahn et al., 2005; Tanner, 2000). The document analysis and interviews furtheridentified five important indicators of reliable certification: the independence of the accreditation body, certification body and standard setter, and monitoring process comprised of document and field inspection.

We posit that existence or nonexistence of these particular components in the structure of a certification indicates the degree of reliability of the certification scheme. For example, certification that is accredited by an accreditation body is considered more reliable than one that is not accredited. Similarly, an independent certification body provides more reliable monitoring than internal certification body due to the elimination of conflict of interest (Deaton, 2004). Following this logic, we propose two major classes for CiTruST, namely:level of trustworthiness and object of trustworthiness.

- Object of trustworthiness refers to components from which users can draw inferences about the trustworthiness of a particular certification. Object of trustworthiness encompasses all classes in CerTIN ontology, particularly: agent, documents, evaluation decision, and inspection process in certification.

- Level of trustworthiness refers to the degree of trustworthiness derived from the conformance or non-conformance to the object of trustworthiness. CiTruST ontology proposes four levels for assessing the trustworthiness of a certification process, ranging from Level A to Level D. The assignment of the level depends on the existence of the criteria in the object of trustworthiness, where level A certification must include all classes specified in the object of trustworthiness, Non-existence of particular classes degrades the level of trustworthiness to level B and so on. For the next stage, we envisioned that CiTruST could map onto different local certification ontologies, such as FLO ontology, to further define the level of reliability for a particular certification scheme. The properties of Level A of trustworthiness from CiTrusT ontology is shown below.

<'Level A of Trustworthiness' conformsto some Standard>

$<$ 'Level A of Trustworthiness' certifiedBy only 'Third Party 


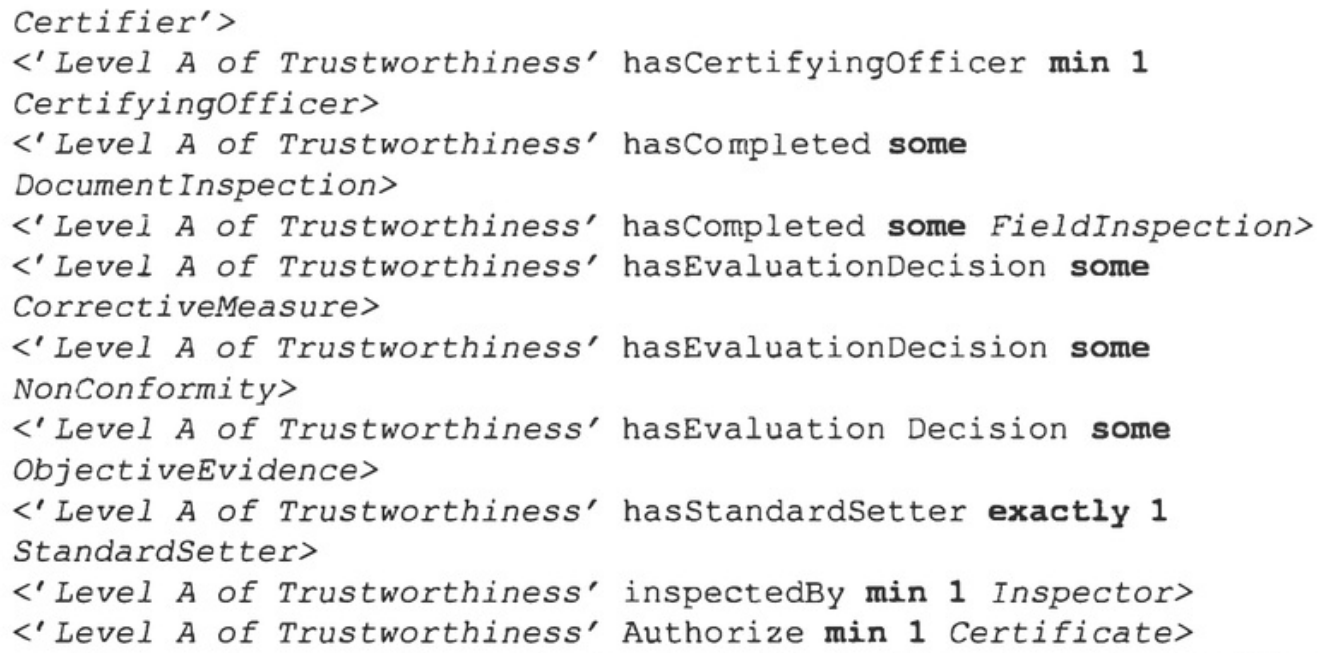

The example provided demonstrates how level of trustworthiness is structured in CiTruST ontology. Detailed explanation of the structure and measurement of the four levels of trustworthiness is available in Luciano et al (2013).

\subsection{Implementation and Verification}

As explained in the methods section, we used two steps to test our ontology. First, we verified consistency of our ontology. Second, we validated our ontology using previously identified competency questions.

1. Verification of Ontology Consistency. We used two reasoners embedded in Protégé to verify our ontology, Hermit ++ and Pellet, and found consistent results from both. To further evaluate the consistency of our ontology, we created instances (individual) in our ontology and re-run the reasoner. Inclusion of instances can highlight if an OWL class is inconsistent (Wang, Horridge, Rector, Drummond, \& Seidenberg, 2005). The inclusion of instances in our ontology did not create any inconsistencies between classes.

2. Verification Through use of Competency Questions. One indication that an ontology is consistent is the ability to query it. Querying in Protégé is possible only after the reasoner is run. We validated our ontology by querying it with previously identified competency questions. We run the query using the DL query ${ }^{11}$ plugin in Protégé. An example of DL query is shown in Figure 4 below.

Question: "Which third-party certifiers are accredited by 1 SO 65?"

\subsection{Architecture for Building Ontology-Based Applications}

In order to answer questions that consumers and consumer advocates might want to know, it is necessary to build applications that can be supported by the ontologies created above. This section describes how these ontologies can support building those applications.

Our ontology can be applied to both small and large databases. As illustrated in Figure 5, the small-scale application happens when only limited data can be accessed, for instance, data in a single database.

However, our ontology is more valuable when it is applied to large-scale data. As shown in Figure 6, data from multiple and heterogeneous sources including expert opinions, the databases of Voluntary Sustainable Certification (VSC) organizations, and the Web are synchronized and integrated through 
Figure 4. Example of DL query and result

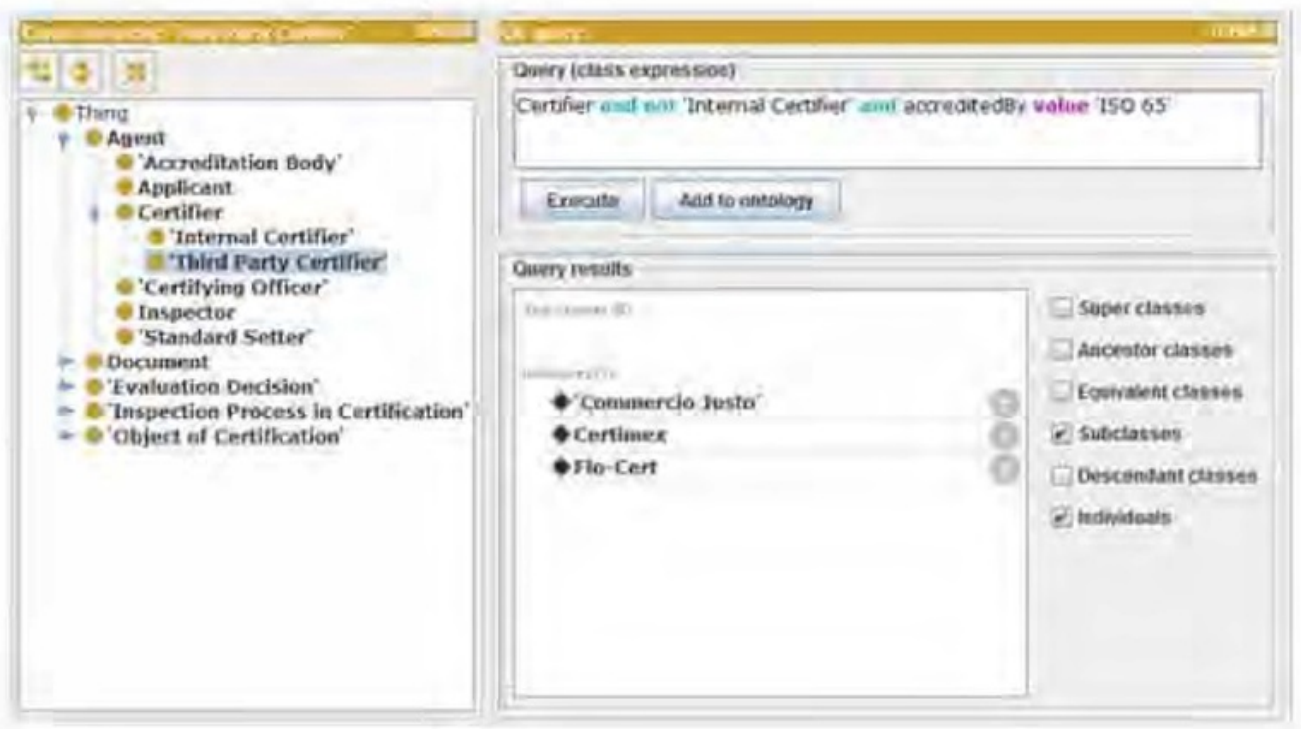

semantic matching with the help of our ontology. This large-scale and integrated data can provide users with more complete and better information.

In both cases, the data and the ontology together form the knowledge base for building applications. The end user can conduct queries using these applications. The application first decomposes a user's natural language query, recomposes it into a query in machine readable format, executes the query against the knowledge base, and finally returns the retrieved information to the end user. If a query request is relatively simple, then the application can execute the query in machine readable format directly. If it is a complex query, then the application needs to rely on a reasoner to retrieve the data. A reasoner is the software that can conduct logical inferences based on rules set to make sense of the data.

\section{DISCUSSION}

In this discussion section, we focus on outlining the value of the proposed certification and inspection ontologies as well as highlighting policy implications of such ontologies.

\subsection{The Envisioned Value of Certification and Inspection Ontology}

In 2011, the U.S. government enacted information policy called smart disclosure policy that gives more power to the consumer to make informed decisions about his/her purchases through the use of information technology and open data (Howard, 2012; Sunstein, 2011). Providing the benefits of smart disclosure to the consumer requires opening data held by the government but also data that is held by private enterprises and third party organizations. This includes disclosing and opening vast amounts of data from disparate data sources. Creating such immense capability requires a combination of technical expertise in terms of interoperable data architecture based on semantic web technology and governance system for such data architecture (Luna-Reyes et al., In Press). In this paper we described 
Figure 5. Architecture for applying the ontology to small-scale data

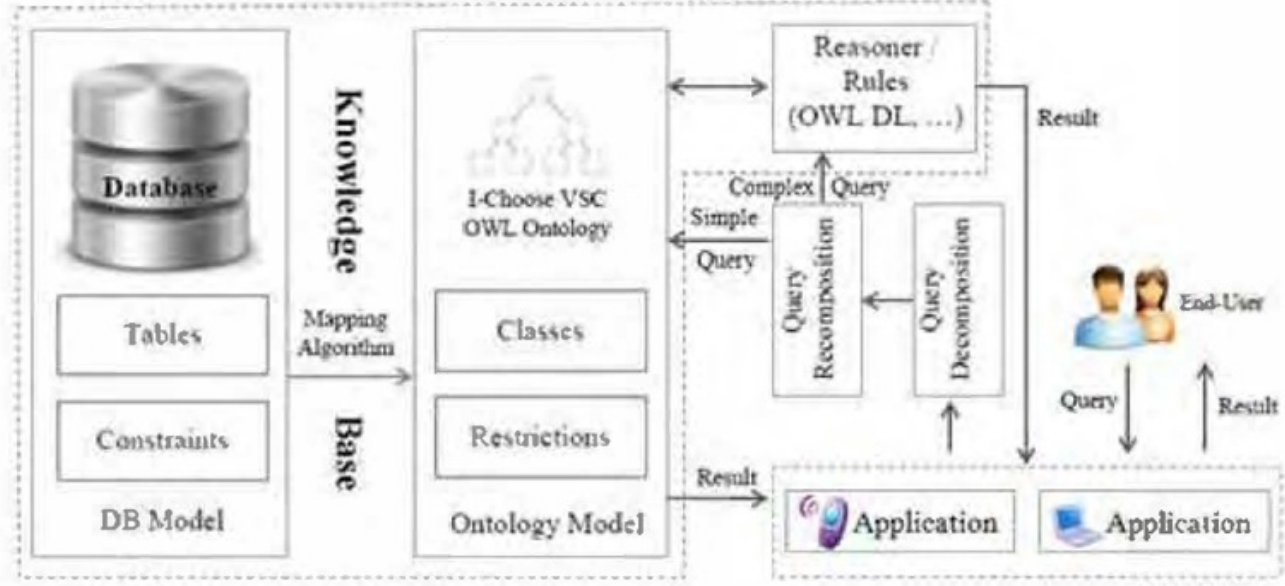

Figure 6. Architecture for applying the ontology to large-scale data

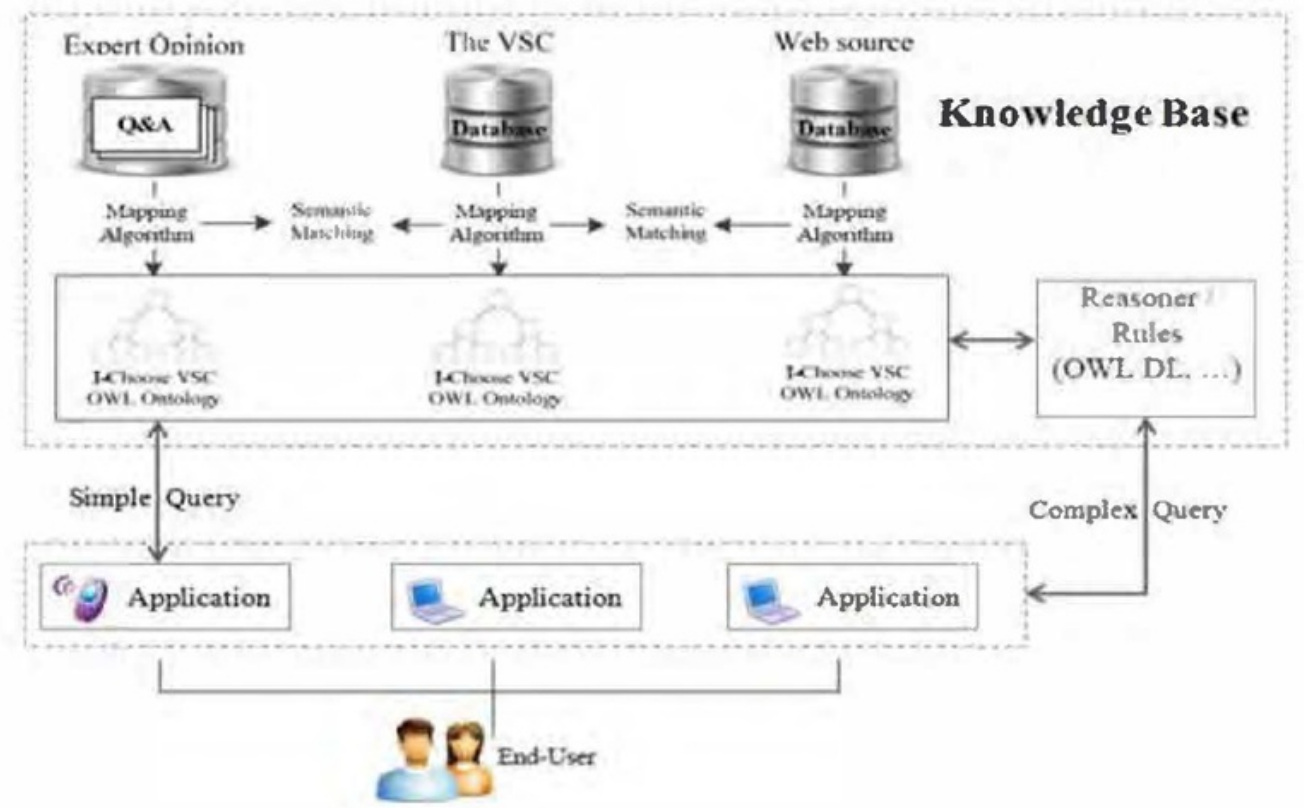


the process involved in developing our ontology of certification and inspection of sustainable products called CerTIN ${ }^{12}$. This ontology has the capability to support implementation of smart disclosure for product attribute information related to certification and inspection.

CerTIN is envisioned to enable data integration and standardization. CerTIN ontology could support knowledge discovery and sharing by synthesizing information across disparate data sources. This integration capability is valuable for informing data-driven policy formulation for governing markets for sustainable products including fair trade. In addition, CerTIN also enables standardization of an agreed set of terms and semantics for currently fragmented certification and inspection schemes. The standardization could support comparability as well as consistent mining of data across different certification schemes.

The comparability capability and integration of data could encourage start-up entrepreneurs in the emerging information aggregation industry to create tools that could help consumers make more informed purchasing decisions. In this way, the information aggregator complements the effectiveness of private regulation in ensuring provision of quality products in the market. The emergence of these information aggregators could then create additional layer of monitoring and policing of private regulations, especially for the currently fragmented certification and inspection ecosystem.

Our proposed ontology demonstrates its integration and standardization capability as it functions as an integrated global ontology that provides a shared vocabulary among all local ontologies. For example, using CerTIN as the basic platform, we used CiTruST ontology to demonstrate how the ontologies could support the comparability functionality to ascertain the trustworthiness of certification processes. This capability could support entrepreneurs providing information about the trustworthiness of a certification scheme, as well as enable consumers to identify differing qualities of certifications. As a global ontology, CerTIN can also map onto local certification ontologies such as FLO to allow consumer advocates assess the trustworthiness of a certification scheme by extracting details from its evaluation process. By comparing evaluation details from different certification schemes, the consumer advocate would be able to recommend a certification scheme with the highest evaluation process quality.

\subsection{Policy Implications of Certification and Inspection Ontology}

In addition to the envisioned value described above, the implementation of such ontology entails several policy implications and benefits.

1. Limiting the Impact of Green Washing: A number of studies indicate that consumers critically questioned the legitimacy of voluntary sustainable certification initiatives. There is an increasing concern that eco-labeling is another form of corporate "greenwash" (Coplan, 2005; Swain, 2011), a marketing effort by companies to exploit the value that consumers place on ethical consumption. Unfortunately, consumers do not have assurances against possible unethical practices by corporations. Efforts to provide more information to consumers through online consumer advocacy also fall short in assuring trustworthy information about certification and labeling as sites such as GoodGuide assign high value to any certification and label without investigating and evaluating the process behind the certification. CerTIN ontology could potentially facilitate a reduction of greenwashing efforts in two ways. First, the ontology enables MTEC such as GoodGuide to extract detailed information on voluntary sustainable certification schemes. Hence, enables them to provide improved advocacy to help consumers with purchasing decisions. Second, the ontology enables consumer advocates and consumers to differentiate between certifications based on the quality of their cvaluation processes.

2. Eliminating Confusion about Product Certifications and Labels Through Market Dynamics: The ontology supports comparability across different certification schemes, which could augment consumers' ability to discipline unethical companies. Consumers have two ways through which they can discipline companies, namely voice and exit (Hirschman, 1970). The ability to 
compare different certification schemes enables consumers to have a better understanding of certifications that adhere to their personal values. Consumers can choose products certified only by a certification that truly reflects their values and has high quality certification processes. These capabilities help in creating demand for specific certification schemes that employ high quality certification processes. These demands create change in the market dynamics. Since quality of certification has an inverse relationship with the cost of certification (Deaton, 2004; Tanner, 2000), the change in market dynamics could result in two plausible conditions. First, product providers need to adjust their practices to have higher quality in terms of ethical, social and environmental values. They need to do so to conform to the requirement of high quality certification schemes otherwise the consumers will not buy their products. Second, the lesser known certification schemes with lower quality certification processes will have to either adjust their practices to provide more support of ethical trading and social and environmental sustainability, or exit from the market.

3. Educating Consumers About Voluntary Sustainable Certification: One of the major difficulties of bringing sustainable consumption issues into the mainstream is the information asymmetry in the supply chain (Seyfang, 2005). Average consumers are not well informed about the meaning of any given certification, which in turn diminishes the value of such certification. Our proposed ontology can be used by start-up entrepreneurs to build an application that could help consumers purchase products that align with their personal social and ethical values. The web or mobile application based on this ontology could inform consumers about how certification systems can actually deliver value, and/or show the transparency of the certification process. This process could enhance consumers' awareness about the certification which may lead to better support for sustainable and ethical consumption.

\section{CONCLUSION}

In this paper we described the ontological modeling process for developing certification and inspection ontologies. We propose three ontologies to support smart disclosure for product information: CertIN, FLO Ontology and CiTruST. Such ontologies that enable detailed description of the process of certification and inspection schemes enables integration and standardization of currently diverse certification and inspection data. We posit that the proposed ontologies could support knowledge discovery and sharing by synthesizing information across disparate data sources, which is valuable for informing data-driven policy formulation. The ontologies also support standardization of an agreed set of terms and semantics for currently fragmented certification and inspection schemes and allow comparability across these schemes. 


\section{REFERENCES}

Albersmeier, F., Schulze, H., Jahn, G., \& Spiller, A. (2009). The reliability of third-party certification in the food chain: From checklists to risk-oriented auditing. Food Control, 20(10), 927-935. doi:10.1016/j. foodcont.2009.01.010

Bartley, T. (2007). Institutional Emergence in an Era of Globalization: The Rise of Transnational Private Regulation of Labor and Environmental Conditions. American Journal of Sociology, 113(2), 297-351. doi: $10.1086 / 518871$

Bartley, T. (2011). Mapping the Hard/Soft Law Terrain: Labor Rights and Environmental Protection: Transnational Governance as the Layering of Rules: Intersections of Public and Private Standards. Theoretical Inq. L., 12, $517-665$

Benartzi, S., Peleg, E., \& Thaler, R. H. (2012). Choice Architecture and Retirement Saving Plans. In E. Shafir (Ed.), The Behavioral Foundations of Public Policy. Princeton University Press.

Bio, L. F. (2013). Semantic Web Misconceptions. Cambridge Semantics - Semantic University. Retrieved from http://www.cambridgesemantics.com/semantic-university/semantic-web-misconceptions

Brusa, G., Caliusco, M. L., \& Chiotti, O. (2006). A process for building a domain ontology: an experience in developing a government budgetary ontology. In M.A. Orgun \& T. Meyer (Eds.), Proceedings of the second Australasian workshop on Advances in ontologies (Vol. 72, pp. 7-15). Hobart, Australia: Australian Computer Society, Inc. Retrieved from http://dl.acm.org/citation.cfm?id=1273661

Büthe, T. (2010a). Global Private Politics: A Research Agenda. Business and Politics, 12(3). doi:10.2202/14693569.1345

Büthe, T. (2010b). Private Regulation in the Global Economy: A (P)Review. Business and Politics, 12(3). doi: $10.2202 / 1469-3569.1328$

Carrigan, M., \& Attalla, A. (2001). The myth of the ethical consumer - do ethics matter in purchase behaviour? Journal of Consumer Marketing, 18(7), 560-578. doi:10.1108/07363760110410263

Standards \& Certification. (n. d.). UTZ Certified. Retrieved from https://www.utzcertified.org/en/ aboututzcertified/standardcertification

Choi, N., Song, I.-Y., \& Han, H. (2006). A survey on ontology mapping. SIGMOD Record, 35(3), $34-41$. doi: $10.1145 / 1168092.1168097$

Coplan, K. S. (2005). Of Zombie Permits and Greenwash Renewal Strategies: Ten Years of New York's SoCalled Environmental Benefit Permitting Strategy. Pace Environmental Law Review, 22, 1.

Cui, Z., Jones, D., \& O'Brien, P. (2001). Issues in ontology-based information integration. In A. G. Perez, M. Gruninger, H. Stuckenschmidt, \& M. Uschold (Eds.), Proceedings of the 1JCAJ-(01 workshop on ontologies and information sharing, Seattle Washington (pp. 141-146).

Deaton, B. J. (2004). A theoretical framework for examining the role of third-party certifiers. Food Control, 15(8), 615-619. doi:10.1016/j.foodcont.2003.09.007

Fairtrade International Standards. (n. d.). FLO. Retrieved from http://www.fairtrade.net/standards.html

Gomez-Pérez, A., Fernandez-Lopez, M., \& Corcho, O. (2004). Ontological engineering: with examples from the areas of knowledge management, e-commerce and the semantic web. London: Springer-Verlag.

Gonzalez, R. (2013). Introduction to the Semantic Web. Cambridge Semantics - Semantic University. Retrieved from http://www.cambridgesemantics.com/semantic-university/introduction-to-the-semantic-web

Hatanaka, M., Bain, C., \& Busch, L. (2005). Third-party certification in the global agrifood system. Food Policy, 30(3), 354-369. doi:10.1016/j.foodpol.2005.05.006

Hirschman, A. O. (1970). Exit, voice, and loyalty: Responses to decline in firms, organizations, and states (Vol. 25). Cambridge, Mass.: Harvard University Press. 
Horridge, M., Knublauch, H., Rector, A., Stevens, R., \& Wroe, C. (2004). A Practical Guide to Building OWL Ontologies Using the Protégé-OWL Plugin and CO-ODE Tools Edition 1.0. The University of Manchester. Retrieved from ftp://gi29.geoinfo.tuwien.ac.at/courses/Ontology/ProtegeOWLTutorial.pdf

Howard, A. (2012). What is smart disclosure? O'Reilly Radar. Retrieved from http://radar.oreilly.com/2012/04/ what-is-smart-disclosure.html

Jahn, G., Schramm, M., \& Spiller, A. (2005). The reliability of certification: Quality labels as a consumer policy tool. Journal of Consumer Policy, 28(1), 53-73. doi:10.1007/s10603-004-7298-6

Janssen, M., \& Hamm, U. (2011). Consumer perception of different organic certification schemes in five European countries. Organic Agriculture (pp. 1-13).

Jarman, H., Luna-Reyes, L. F., Zhang, J., Whitmore, A., Picazo-Vela, S., \& Andersen, D., ... Sayogo, D. (2011). I-Choose: Consumer choice, digital government, and sustainability in North America. Presented at the APPAM Research Conference, Washington DC.

Luciano, J. S., Jarman, H., Sayogo, D., Ran, W., Depaula, N., Luna-Reyes, L., . . Pardo, T. (2013). 1s Big Data Enough? An Empirical Evaluation of Governance Requirements for Certification and Inspection Data in Support of Consumer Choice (Working Paper). Center for Technology in Government, Albany, NY.

Luna-Reyes, L. F., Zhang, J., Whitmore, A., Jarman, H., Picazo-Vela, S., Andersen, D. L., \& Andersen, D. F. et al. (in press). Full Information Product Pricing: An Information Strategy for Harnessing Consumer Choice to Create a More Sustainable World. Communications of the Association for Information Systems.

Makower, J. (2010, November 1). 1s TerraChoice Greenwashing? GreenBiz.com. Retrieved from http://www. greenbiz.com/blog/2010/1 1/01/terrachoice-greenwashing

Mayer, F., \& Gereffi, G. (2010). Regulation and Economic Globalization: Prospects and Limits of Private Governance. Business and Politics, 12(3). doi:10.2202/1469-3569.1325

Noy, N. F., \& McGuinness, D. L. (2001). Ontology development 101: A guide to creating your first ontology (Technical Report No. SMI-2001-0880). Stanford knowledge systems laboratory, Stanford, CA.

Polonsky, M., Bhaskaran, S., \& Cary, J. (2011). Exploring the opportunities for sustainable food labelling: a supply chain perspective. Proceedings of the Australian and New Zealand Marketing Association Conference ANZMAC '05 (pp. 184-190).

Ramus, C. A., \& Montiel, I. (2005). When Are Corporate Environmental Policies a Form of Greenwashing? Business \& Society, 44(4), 377-414. doi:10.1177/0007650305278120

Semy, S. K., Pulvermacher, M. K., \& Obrst, L. J. (2004). Toward the use of an upper ontology for US government and US military domains: An evaluation (DTIC Document). Retrieved from http://oai.dtic.mil/oai/oai?verb=ge tRecord\&metadataPrefix $=$ html\&identifier=ADA459575

4 Seyfang, G. (2005). Shopping for sustainability: Can sustainable consumption promote ecological citizenship? Environmental Politics, 14(2), 290-306. doi:10.1080/09644010500055209

Sunstein, C. R. (2011). Informing Consumers through Smart Disclosure (Memorandum for the Heads of Executive Departments and Agencies). Washington D.C.: Office of Management and Budget, The White House. Retrieved from http://www.whitehouse.gov/blog/2012/03/30/informing-consumers-through-smart-disclosure

Swain, G. (2011, November 16). On the Alert for Misleading Ads. The New York Times. Retrieved from http:// green.blogs.nytimes.com/2011/11/16/on-the-alert-for-misleading-ads/

Tanner, B. (2000). Independent assessment by third-party certification bodies. Food Control, 11(5), 415-417. doi:10.1016/S0956-7135(99)00055-9

Taylor, P. L., Murray, D. L., \& Raynolds, L. T. (2005). Keeping trade fair: Governance challenges in the fair trade coffee initiative. Sustainable Development, 13(3), 199-208. doi:10.1002/sd.278

Thaler, R. H., \& Sunstein, C. R. (2008). Nudge: Improving Decisions about Health, Wealth, and Happiness. Yale University Press. 
Thaler, R. H., Sunstein, C. R., \& Balz, J. P. (2010). Choice Architecture (SSRN Scholarly Paper No. ID 1583509). Rochester, NY: Social Science Research Network. Retrieved from http://papers.ssrn.com/abstract=1583509

Wang, H., Horridge, M., Rector, A., Drummond, N., \& Seidenberg, J. (2005). Debugging OWL-DL Ontologies: A Heuristic Approach. In Y. Gil, E. Motta, V. R. Benjamins, \& M. A. Musen (Eds.), The Semantic Web-ISWC 2005 (pp. 745-757). Springer Berlin Heidelberg. Retrieved from http://link.springer.com/chapter/10.1007/1 1574620_53 doi:10.1007/11574620_53

Watts, S., \& Wyner, G. (2011). Designing and theorizing the adoption of mobile technology-mediated ethical consumption tools. Information Teclnology \& People, 24(3), 257-280. doi:10.1 108/09593841111158374

\section{ENDNOTES}

1 Greenwashingrefers to "the application of an environmentally friendly sounding name to an environmentally unfriendly practice" (Bartley, 2007, p.2)

$z$ Different certification schemes use different terms to name actors conducting comparable and similar functions. For instance, FLO uses auditor which is comparable to inspector who conducts inspections/ audits.

3. FLO is short for Fairtade Labeling Organization, a third party standard body that develops certification standards to encourage fair trading and assist small producers with gaining and maintaining certification (http://www.fairtrade.net/what-is-fairtrade.html)

$4 \quad$ UTZ Certified is a third party certification that promotes sustainable farming and better opportunitics for farmers of coffee, cocoa and tea and their families through improvement of farming methods, working conditions and better care for their children and environment (https://www.utzcertified.org/).

s. Flo-Cert is a certification body that conducts certifications on behalf of FLO International.

6 http://dublincore.org/2008/01/14/dcternns.rdf

7 http://xmlns.com/foaf/spec/

8 http://www.heppnetz.de/projects/goodrelations/

9 http://www.w3.org/wiki/Good_Ontologies

10 This is a commonly used term and is equivalent to a certification body.

11 DL query is query language that is based on the Manchester OWL syntax.

12 The ontology and our project documentations are available at http://ichoose.tw.rpi.eduorhttps://github.com/ jluciano/ichoose/blob/master/data/source/ctg-albany-edu/ontologies/version/latest/manual/certification. owl 
Ontological Modeling of Certification and Inspection Process to Support Smart Disclosure of Product Information

ORIGINALITY REPORT

$4 \%$

SIMILARITY INDEX
$4 \%$

INTERNET SOURCES
$7 \%$

PUBLICATIONS
$7 \%$

STUDENT PAPERS

\section{PRIMARY SOURCES}

1 Smarter as the New Urban Agenda, 2016.

2 repository.tudelft.nl

3 P. Jayashree, K.S. Easwarakumar,

Anandharaman V., Aswin K., Raja Vijay S.. "A

Proactive Statistical Defense Solution for

DDOS Attacks in Active Networks", 2008 First

International Conference on Emerging Trends

in Engineering and Technology, 2008

Publication

"Challenges to Developing Interoperable Data

Architecture to Support Sustainable

Consumption and Sustainable Supply Chains",

Private Data and Public Value, 2016. 
Exclude quotes

On

Exclude matches

$<1 \%$

Exclude bibliography

On 